\title{
Personalized Nutrition as a Key Contributor to Improving Radiation Response in Breast Cancer
}

\author{
Anuradha A. Shastri ${ }^{1}{ }^{1}$, Joseph Lombardo ${ }^{1}$, Samantha C. Okere ${ }^{1}$, Stephanie Higgins ${ }^{1}$, Brittany C. Smith ${ }^{1}$, \\ Tiziana DeAngelis ${ }^{1}$, Ajay Palagani ${ }^{1}$, Kamryn Hines ${ }^{1}$, Daniel A. Monti ${ }^{2}$, Stella Volpe ${ }^{3}$, Edith P. Mitchell ${ }^{4}$ \\ and Nicole L. Simone ${ }^{1, *(D)}$
}

1 Department of Radiation Oncology, Sidney Kimmel Cancer Center, Thomas Jefferson University, Philadelphia, PA 19107, USA; axs791@jefferson.edu (A.A.S.); Joseph.Lombardo@jefferson.edu (J.L.); Samantha.Okere@students.jefferson.edu (S.C.O.); Stephanie.Higgins@students.jefferson.edu (S.H.); bs252869@pcom.edu (B.C.S.); Tiziana.DeAngelis@jefferson.edu (T.D.); ajaypalagani@gmail.com (A.P.); Kamryn.Hines@jefferson.edu (K.H.)

2 Department of Integrative Medicine and Nutritional Sciences, Marcus Institute of Integrative Health, Thomas Jefferson University, Philadelphia, PA 19107, USA; daniel.monti@jefferson.edu

3 Department of Human Nutrition, Foods and Exercise, College of Agriculture and Life Sciences, Virginia Tech, Blacksburg, VA 24061, USA; stellalv@vt.edu

4 Department of Medical Oncology, Sidney Kimmel Cancer Center, Thomas Jefferson University, Philadelphia, PA 19107, USA; edith.mitchell@jefferson.edu

* Correspondence: nicole.simone@jefferson.edu

\section{check for} updates

Citation: Shastri, A.A.; Lombardo, J.; Okere, S.C.; Higgins, S.; Smith, B.C.; DeAngelis, T.; Palagani, A.; Hines, K.; Monti, D.A.; Volpe, S.; et al. Personalized Nutrition as a Key Contributor to Improving Radiation Response in Breast Cancer. Int. J. Mol. Sci. 2022, 23, 175. https://doi.org/ 10.3390/ijms23010175

Academic Editors: James A. Bonner and Christopher D. Willey

Received: 1 December 2021

Accepted: 23 December 2021

Published: 24 December 2021

Publisher's Note: MDPI stays neutral with regard to jurisdictional claims in published maps and institutional affiliations.

Copyright: (C) 2021 by the authors. Licensee MDPI, Basel, Switzerland. This article is an open access article distributed under the terms and conditions of the Creative Commons Attribution (CC BY) license (https:// creativecommons.org/licenses/by/ $4.0 /)$.

\begin{abstract}
Understanding metabolic and immune regulation inherent to patient populations is key to improving the radiation response for our patients. To date, radiation therapy regimens are prescribed based on tumor type and stage. Patient populations who are noted to have a poor response to radiation such as those of African American descent, those who have obesity or metabolic syndrome, or senior adult oncology patients, should be considered for concurrent therapies with radiation that will improve response. Here, we explore these populations of breast cancer patients, who frequently display radiation resistance and increased mortality rates, and identify the molecular underpinnings that are, in part, responsible for the radiation response and that result in an immunesuppressive tumor microenvironment. The resulting immune phenotype is discussed to understand how antitumor immunity could be improved. Correcting nutrient deficiencies observed in these populations should be considered as a means to improve the therapeutic index of radiation therapy.
\end{abstract}

Keywords: breast cancer; radiation therapy; nutrient; African American; obesity; metabolic syndrome; aging

\section{Introduction}

To date, radiation regimens for breast cancer are chosen and administered based on a patient's tumor type and stage; typically, the only aspect of a radiation regimen that is changed is dosing, fractionation, overall treatment time, and volume of the breast and normal tissue treated. This approach works for a majority of patients since local recurrence rates are low for most breast cancer [1,2]. Since there is evidence that optimal local tumor control portends improved survival and fewer metastases, attention should turn toward differentiating which tumor types or patient characteristics might be associated with poor outcomes despite adequate radiation therapy (RT). It has been established that certain patient characteristics or underlying tumor genetic milieu are associated with varying degrees of radiation sensitivity and these are not accounted for [3]. Despite this finding, to date, there are scarce data for combining radiation with systemic therapies including chemotherapy or immunotherapy to improve the effect of radiation.

After the explosion of the understanding of genomic mutations and technology approaches for sequencing, the last two decades have been met with precision medicine 
approaches to understanding how tumors are growing and progressing [4]. Although chemotherapy and other systemic treatments have been tailored by genomic alterations for some women with breast cancer, successful modifications to radiation therapy regimens have been mostly limited to changes in the number of fractions or doses given. Genetic signatures of a patient's tumor have been used to determine if a breast cancer patient would benefit from chemotherapy. Genomic profiling of tumors has also been used to guide treatment decisions for metastatic breast cancer patients and prostate cancers of various risks. Unfortunately, few approaches to genomic profiling have been devised to assess radiation response with the most notable including the radiation sensitivity index [5]. To our knowledge, genomic indicators of radiation response have not yet been used to alter radiation regimens. Despite the increase in precision medicine approaches, significant, improved cancer outcomes have not followed.

Simultaneously, the last two decades have also brought a change in the United States patient population without adaptation of radiation based on the characteristics of our population. Patients with obesity, metabolic syndrome, advanced age, and diverse communities have increased with time and are known to have varying levels of radiation sensitivity [6-8]. This is likely, in part, due to alteration of specific molecular pathways that are associated with a decrease in antitumor immunity, which can influence tumor biology and response to radiation. Additionally, these patient populations often have specific nutritional deficiencies that further dysregulate metabolic pathways and immune response. Understanding nutritional deficiencies in various populations of patients may provide insight into nontoxic methods to increase radiation responsiveness. Precision nutrition, defined as an approach that is tailored based on hosts genetic, phenotypic, microbiome profiles, and medical history $[9,10]$, has long been used to treat nutrient deficiency based diseases including scurvy, anemia, osteoporosis, etc., and micronutrient deficiencies have also been shown to trigger DNA damage and increase risk of cancers [11]. Recent studies have shown the benefit of applying precision nutrition to target specific metabolic pathways and preventing cancer relapse in multiple cancers including breast cancer [12,13]. Precision nutrition has also been shown to modulate the gut microbiome, foods rich in phytochemicals and omega-3 fats have been shown to alter the microbiome and increase the abundance of anti-inflammatory bacteria that help prevent cancer progression [14,15]. In the current narrative review, we discuss populations with known differences in radiation outcome-African Americans, obese patients or those with metabolic syndrome, and the aging population. We then explore probable mechanisms by which precision nutrition interventions could be used to improve radiation response in nutrient-deficient resistant breast cancer patients, leading to enhanced tumor control and/or less radiation toxicity while decreasing the inequity of outcomes.

We propose that improving radiation response can only be accomplished if a patient's baseline characteristics, which are observed to have associated alteration in metabolic and immune function, are accounted for as these directly influence the tumor and the tumor's response to therapy. To identify ways to personalize radiation, here, we discuss specific patient populations known to be associated with poor radiation response and their associated molecular underpinnings, and we identify precision nutrition approaches to improving radiation sensitivity to improve cancer outcomes for all patients. The future of radiation oncology, moving toward precision radiation, will need to account for molecular underpinnings specific to host populations and implement combination therapy strategies to even the playing field for all patients receiving radiation.

\section{Breast Cancer and Radiation Response in the African American Population}

From 2008 to 2012, the incidence of breast cancer has increased among the United States African American (AA) population, as per the American Cancer Society [16]. There is also a mortality disparity with African American women, having a $42 \%$ higher mortality rate than Caucasian women nationwide [16]. Unfortunately, it has also been shown that the mortality increase for African American women holds for all breast cancer subtypes, 
including estrogen positive, her-2-neu positive, and triple-negative breast cancers [17]. The cause for the observed disparity is multifactorial and includes differences in genetics, a socioeconomic status that often delayed access to care and treatment, and toxicities due to treatment that weakens the overall prognosis [18].

\subsection{Molecular Disparity in African American Breast Cancer Patients}

It is established that some of the disparity in breast cancer outcomes may be related to the more notable dysregulation of the IGF-1R pathway in African American patients. African American patients suffer disproportionally, compared with their Caucasian peers, with metabolic problems that affect the IGF-1R pathway. Comorbidities such as diabetes, abdominal obesity, dyslipidemia, glucose intolerance, and metabolic syndrome (MetS) are higher in the African American community and lead to upregulation of the IGF-1R signaling pathway [19]. IGF-1R is expressed significantly more in African American normal tissue, compared with that of Caucasian patients [20], and specifically more in the breast tissue [21], with increased dysregulation in cancers.

In breast cancer, metabolism is, in part, responsible for metastatic spread via dysregulation of the IGF-1R/Akt pathway, which directly influences tumor progression and plays a role in the fate of anchoring metastases to the tumor microenvironment [22-24]. IGF-1R overexpression is associated with decreased breast cancer survival, increases in recurrence, and treatment resistance to radiation and Herceptin, which are both used to treat brain metastases [25-27]. In addition, IGF-1 and IGF binding protein 3 are also associated with breast cancer risk, progression, recurrence, and the probability of survival in African American women $[28,29]$. Therapies that can be added to radiation that increase local control and metastases would be optimal.

\subsection{IGF-1R and Radiation Response}

Upregulation of IGF-1R, which is notable in the African American community, is also associated with increased radiation resistance due to decreases in apoptosis and antitumor immunity [30-32].

The influence of IGF-1R signaling after radiation may influence cancer cell survival due to alterations in apoptotic response. The mechanism by which IGF-1R is believed to cause resistance to radiation therapy and increase cell survival is by acting on the BCL2/BAD complex to inhibit BAD through phosphorylation, thereby releasing antiapoptotic BCL-2, and preventing apoptosis. IGF-1R also curbs apoptosis in coordination with major vault protein (MVP), which itself inhibits PTEN and increases inhibition of apoptosis through activation of PI3K/Akt [33]. When the apoptosis mechanism is not optimally functional, the DNA damage induced by radiation therapy that is left unrepaired is unable to be followed by apoptosis. Further, a combination of overexpression of IGF-1R and radiationinduced non-homologous end joining (NHEJ) leads to downregulation of apoptosis and thus radiation resistance [33,34].

IGF-1R upregulation also directly creates an immune-suppressive environment that further accentuates radiation resistance with a decrease in antitumor immunity via CD8+ T cells and M1 macrophages and an increase in regulator T cells and M2 macrophages. In in vivo breast cancer models, the inhibition of IGF-1R reduced tumor growth and increased the CD8+-mediated immune response in the tumor while reducing immunosuppressive regulatory T cells. Although African American women with breast cancer are noted to have higher levels of CD8+ T cells, as noted in a study of 688 invasive breast cancer tumor samples (550 Black and 138 White), it has been shown that the high CD8+ proportion does not translate to a better prognosis in AA women, because the CD8+ population is made up of a higher percentage of exhausted CD8+ T cells, which is linked to lower survival [35,36].

Similarly, while CD8+ T cells are reported to be a marker for favorable prognosis, immunosuppressive regulatory $\mathrm{T}$ cell (Treg) infiltrates are associated with distant metastases, worse survival [37], and radiation resistance [38]. In fact, Treg ablation has been found to significantly improve ionizing radiation therapy [39]. Unfortunately, Tregs have 
consistently been shown to be higher in AA patients, compared with CC patients [40]. Tumor-associated macrophages are known to secrete IGF-1/IGF-2 in the tumor microenvironment. The activation of the IGF-1R/Akt pathway triggers increased infiltration of the M2 macrophages, leading to tumor progression and decreased overall survival in breast cancer patients. AA women have increased proliferation of immunosuppressive M2 macrophages, as compared with M1 macrophages, which may inhibit CD8+ action [41]. "M2-shifted" groups are strongly associated with decreased disease free-survival, lending to the idea that standard BCT alone may be insufficient for these patients $[41,42]$. Tumor-associated M2 macrophages suppress postradiation therapy antitumor immunity, which promotes tumor regrowth and angiogenesis [43-45] and radiation therapy resistance [46,47].

Ultimately, the increase in the IGF-1R signaling pathway leads to tumor invasion and metastasis with evasion from the immune system, which contributes to radiation resistance and poor breast cancer outcomes in AA patients [48]. This may be, in part, due to increased rates of obesity in African American women, which is often associated with insulin resistance and dysfunction of IGF-1R [49,50]. Taken together, standard radiation regimens may not be sufficient for AA patients with breast cancer due to the underlying molecular alterations in the IGF-1R signaling pathway.

\subsection{Vitamin D Supplementation and IGF-1R to Improve Radiation Response}

Since African American breast cancer patients have upregulation of the IGF-1R signaling pathway, which is associated with poor radiation response, identifying a mechanism to downregulate the pathway could optimize radiation response. Interestingly, it is well known that vitamin D can downregulate the IGF-1R signaling pathway. In vitro studies carried out on breast cancer cells showed that vitamin D treatment can downregulate the IGF-1R pathway and increase apoptosis [51]. Vitamin D and its analogs have also been shown to suppress IGF-1-induced growth of breast cancer cells by downregulating IGF and IGF-1R and increasing IGF-BP expression [52]. In addition, most African American women have a vitamin D deficiency. Here, we explore the link and show preliminary data demonstrating the possible benefit of vitamin $\mathrm{D}$ in regulating radiation response.

\subsection{Vitamin D Deficiency in AA Patients}

Vitamin D deficiency is a common presentation for African American patients. This can be attributed to several factors including darker skin pigmentation, low dietary vitamin D, and obesity. Vitamin D synthesis from sun exposure to skin provides $50-90 \%$ of vitamin $\mathrm{D}$ in the human body, the remainder comes from dietary and supplementary intake [53]. The concentration of melanin in the skin of the AA population dramatically suppresses the cutaneous synthesis of vitamin D by preventing the penetration of UVB light. While this is beneficial when living in areas of intense sunlight such as equatorial Africa, or more tropical climates where that protection is needed while still allowing for adequate vitamin D production, dark skin pigmentation puts African Americans living in non-tropical areas at higher risk of vitamin D deficiency. Additionally, since vitamin D is a fat-soluble vitamin, it may be sequestered by adipose tissue, which lowers physiologically availability in circulation, and unfortunately, the African American population in our country has higher rates of obesity, compared with European Americans [54].

\subsection{Vitamin D and Breast Cancer}

Multiple studies demonstrate that low vitamin D levels correlate to the risk of breast cancer and worse breast cancer outcomes. Vitamin D deficiency has been shown to increase breast cancer susceptibility by approximately $23 \%$ in AA women, indicating vitamin D intake could be considered a preventative factor for breast cancer incidence [55]. Higher vitamin $\mathrm{D}$ intake has been linked with decreased breast density, which is associated with decreased risk of breast cancer [56]. Increased overall survival, especially in premenopausal women, was associated with an elevation in serum $25(\mathrm{OH}) \mathrm{D}$ concentrations in a recent cohort study that included 1666 women diagnosed with breast cancer [55]. The mechanism 
by which vitamin $\mathrm{D}$ may prevent breast cancer and lead to improved cancer outcomes may be, in part, due to the downregulation of the IGF-1R pathway.

\subsection{Immune Response and Radiation Response}

Vitamin D may help address the immune dysfunction associated with IGF-1R dysregulation seen in AA breast cancer patients. In the presence of vitamin D, breast tumors showed an increase in tumor-infiltrating CD8+ T cells that were functionally active. Interestingly, a high-fat diet was shown to reverse this vitamin-D-induced increase in tumor-infiltrating CD8+ T cells, highlighting the importance of diet in tumor growth [57]. Vitamin D has also been shown to induce Foxp3+ Treg cells, making them less immunosuppressive [58].

As we have discussed above, AA patients have a higher incidence of vitamin D deficiency, and vitamin $\mathrm{D}$ has shown some promise in breast cancer incidence and outcomes [54]. Diet is a major contributor to health disparity in breast cancer and other chronic diseases. A person's diet can increase or decrease his or her risk for cancer. Nutritional factors including dietary fat, meat, fiber, and vitamin D have been investigated as either promoting or inhibiting breast cancer development and survival [59]. The active form of vitamin D has been shown to efficiently contribute to increased genomic instability in response to radiation [60].

\subsection{Vitamin D Supplementation to Improve Radiation Response in African American Women}

In Figure 1, we summarize the factors responsible for the poor radiation response observed in African American women and hypothesize that supplementation with vitamin $\mathrm{D}$ will improve the radiation response to tumors in this population. We propose that the mechanism by which vitamin $\mathrm{D}$ will improve tumor response is by increasing antitumor immunity and insulin response, thereby preventing inflammation-related radioresistance.
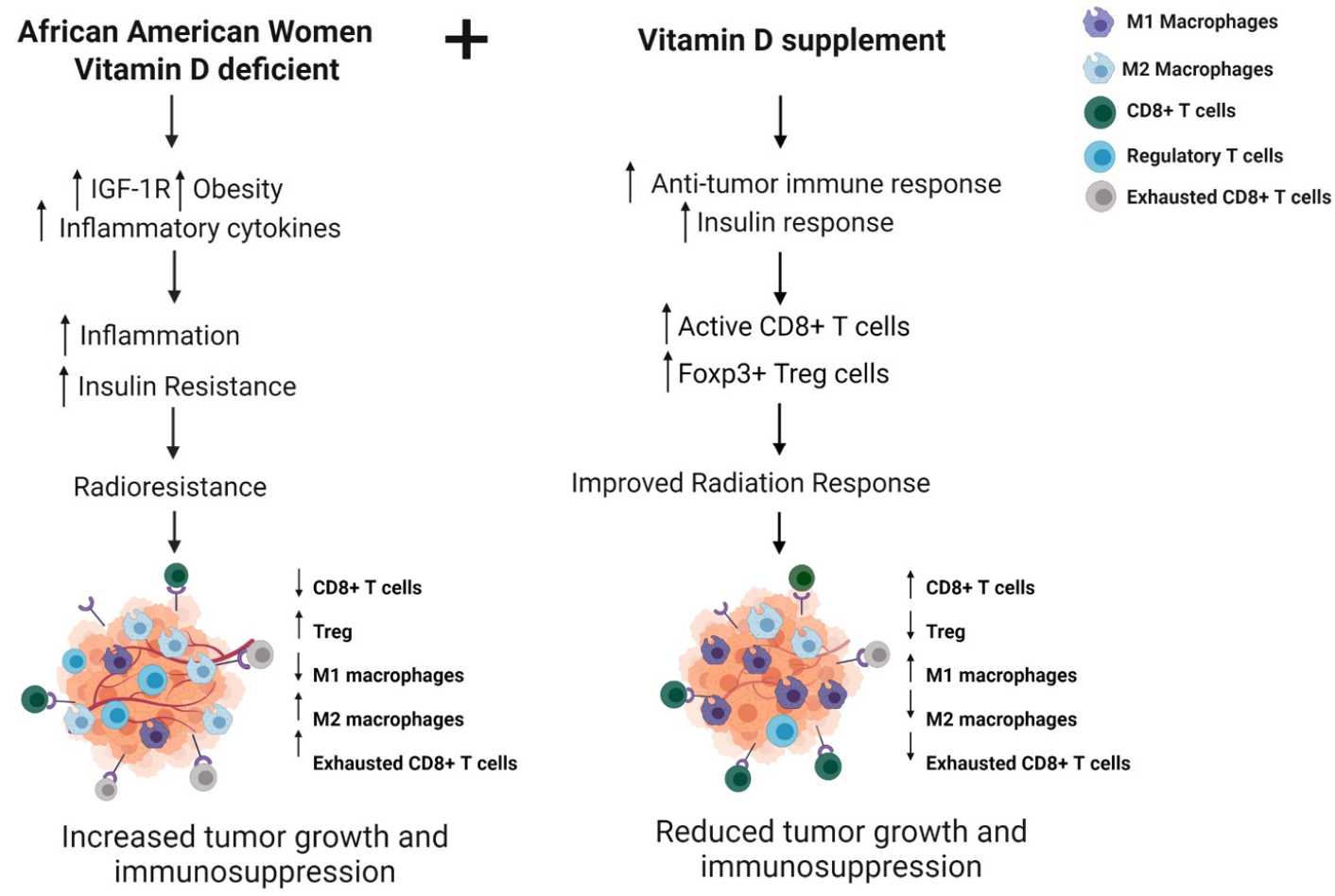

Figure 1. Vitamin D supplementation to modulate antitumor immune response and radiation sensitivity in African American breast cancer patients. Vitamin D deficiency is prevalent in African American women and is associated with upregulation of the IGF-1R signaling pathway with resulting immunosuppression and increase in inflammatory cytokine levels leading to tumor growth and radiation resistance. Modeling supplementation with vitamin D, radiation response would improve by increasing antitumor immune response. Created with BioRender.com. 


\section{Obesity, Metabolic Syndrome, and RT}

Breast cancer patients who are obese or have metabolic syndrome have an increased risk of breast cancer, worse cancer outcomes, and radiation resistance [61]. According to the CDC, the prevalence of obesity among adults in the United States is $42.5 \%$, with $9.2 \%$ being severely obese [62]. It has been found that metabolic syndrome leads to a $47 \%$ increase in relative risk of breast cancer [63], which spans across all breast cancer subtypes [64,65].

Mechanistically, patients who are obese or have metabolic syndrome commonly have insulin resistance and an adipokine imbalance, which results in systemic inflammation that is known to be associated with disease progression and work outcomes.

The insulin resistance results in increased production of IGF-1, resulting in upregulation of the IGF-1R/AKT pathway, promoting carcinogenesis, angiogenesis, migration, and invasion. IGF-1R also inhibits apoptosis [66,67].

The adipokine imbalance is notable for a decrease in levels of adiponectin, with increased leptin levels. This combination negatively regulates inflammation and cell proliferation, leading to increased breast cancer risk $[68,69]$, cell proliferation, migration, and invasion [70]. Unfortunately, the adipokine imbalance plays a role in proinflammatory pathways, resulting in the release of TNF- $\alpha$, IL-1, IL- 6 , and IL-12 and reactive oxygen species (ROS) [68]. Systemic inflammation due to obesity/metabolic syndrome results in lipolysis, which releases free fatty acids (FFAs). FFAs stimulate TLR4 present on breast cancer cells, activating NF-kB, which increases cancer stem cells. The inflammatory cytokines, including IL-8, IL-6, CCL2, CCL5, and IP-10 produced from adipocytes, promote cancer stem cell expansion.

In the setting of obesity and insulin resistance, immune dysfunction is prevalent. The tumor microenvironment in obese patients has increased Tregs, exhausted CD8+ T cells, and increased M2 macrophages. Tumor cells in the setting of obesity are stimulated by inflammatory cytokines and make CCL22, which recruits Tregs that have an inhibitory effect on the antitumor function of CD8+ T cells [18]. A study in obese mice showed that the mice produced high amounts of leptin that activated STAT3 in CD8+ T cells, promoting fatty acid oxidation. Fatty acid oxidation in CD8+ T-effector cells decreased their antitumor function, resulting in T cells with an exhausted phenotype [71], thereby promoting breast tumorigenesis [72]. Tissue exposed to inflammatory cytokines, as with obesity, switches from M1 to M2 macrophages [73], which produce epithelial growth factor (EGF) and tumor growth factor-beta (TGF- $\beta$ ), thereby promoting tumor invasion and metastasis [50].

\subsection{Obesity/Metabolic Syndrome and Radiation Response and Toxicity}

Prior studies have demonstrated that obesity and associated insulin resistance portends for poor outcomes and radiation response. A recently published large meta-analysis of over 200 studies shows obesity was associated with decreased overall survival (HR, 1.14; $95 \%$ CI, 1.09-1.19; $p<0.001$ as well as cancer-specific survival, $p<0.001$ [74]. Specifically, in breast cancer, obese patients have up to a $40 \%$ increased risk of breast cancer recurrence [75]. Obese women are also known to have a greater incidence of metastatic disease from breast cancer [76]. For women with diabetes who develop breast cancer, population-based studies have shown that even with similar cancer treatment, women with an extended history of diabetes had a higher all-cause and breast-cancer-specific mortality [77].

Preclinical studies have linked obesity and insulin resistance as seen in metabolic syndrome with cancer progression through immune evasion and radiation resistance [6]. Obese breast cancer patients who received whole-breast radiation were $12.6 \%$ more likely to have local recurrence after five years. Kim et al. showed that adipose stem cells, together with leptin in the tumor microenvironment, were responsible for the obesity-associated radiation resistance through upregulation of NOTCH and IL-6 [78]. In addition to the understanding that obesity and metabolic syndrome impact outcomes at initial diagnosis, it has also been demonstrated that obesity and diabetes impact outcomes for metastatic patients. Patients with breast cancer brain metastases who were either obese or diabetic and 
were treated with whole-brain radiation showed decreased overall and progression-free survival [6].

Obese patients have been shown to suffer from worse radiation-induced toxicities than patients with normal BMI. Obese breast cancer patients show an increase in inflammatory biomarkers due to radiation causing skin toxicity. Obese patients have increased pain, worse functional well-being during treatment, and slower improvement [79]. An increase in inflammatory biomarker CRP is also seen, which is linked to the radiation-induced early adverse skin reactions (EASR). Obesity-related increase in inflammation increases EASR and causes changes in proinflammatory, proangiogenic, profibrotic cytokines resulting in increased normal tissue toxicity [80]. High BMI in breast cancer patients has also been linked to worse acute treatment outcomes and lower quality of life pre, during, and postradiation treatment. Obesity is also linked to a worse FACT g score and physical well-being score. Patients with high BMI reported worse symptoms including fatigue, drowsiness, shortness of breath, and pain [81]. Higher BMI is also associated with an increase in the development of radiation dermatitis after radiation therapy following breast-conserving surgery. Larger breast size has also been associated with increased toxicity due to higher dosage and dose homogeneity [82].

\subsection{Magnesium in Obesity/Metabolic Syndrome and Breast Cancer}

Hypomagnesemia is commonly observed in patients with metabolic syndrome and obesity. Magnesium plays a role in glucose metabolism and insulin signaling, regulating tyrosine kinase activity and glucose transporter protein activity 4 (GLUT4), leading to glucose translocation into the cell [83]. In their study with metabolic syndrome patients, Guerrero-Romero et al. showed that hypomagnesemia was linked with dyslipidemia, hypertension, and insulin resistance. Magnesium supplementation improved insulin sensitivity [84]. Hruby et al. showed that, compared with the control group, participants with the highest magnesium intake had a $47 \%$ reduced risk of metabolic disorder or diabetes incidence and had lowered fasting glucose and insulin resistance [85]. Volpe suggests that if magnesium supplementation affects insulin sensitivity in participants with diabetes mellitus, it may also improve insulin sensitivity in obese individuals at risk of type 2 diabetes mellitus [83]. Supplementation with magnesium in overweight subjects with insulin resistance for six months resulted in a significant difference in fasting glucose and insulin sensitivity [86]. Similarly, another study showed that higher dietary magnesium intake was strongly associated with the attenuation of insulin resistance and was more beneficial for overweight and obese individuals in the general population and premenopausal women [87].

Magnesium deficiency has been shown to both protect against and increase the risk of breast cancer. It plays a vital role in the cell cycle, and hence, its deficiency influences precancerous transformation [88]. Magnesium is also involved in acquiring immunocompetence and increased levels indicate protection from cancer [89]. Huang et al. have shown that breast cancer risk was reduced in those with higher intake of magnesium through a direct effect on breast cancer and an indirect effect by reducing CRP levels [90]. Low intracellular magnesium levels at the beginning of tumorigenesis are associated with cancer development and progression due to impaired antioxidant defense and increased inflammation [91]. Low magnesium levels also induce nitric oxide production, leading to the production of VEGF and angiogenesis, which leads to an increase in angiogenesis [92]. Contradictory studies have shown that high magnesium levels can stimulate breast cancer development at the early stages of tumorigenesis by regulating enzymes and genes that trigger energy generation and inhibit apoptosis [93-96].

\subsection{Magnesium Supplementation to Improve Radiation Response}

In Figure 2, we summarize the factor responsible for the poor radiation response that is observed in obese breast cancer patients or those with metabolic syndrome. Since magnesium is involved in the regulation of insulin signaling, leptin metabolism, and 
the immune response, we hypothesize that supplementation with magnesium in this population would help increase the efficiency of radiation therapy and tumor response by reducing levels of inflammatory markers and improving insulin response, thereby preventing tumor progression, reducing toxicities, and improving breast cancer outcomes in this population.

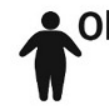

Obesity/Metabolic Syndrome Magnesium Deficient

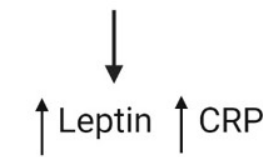

Insulin resistance<smiles>CCC(CC)[C@H](C)O</smiles>

Radioresistance

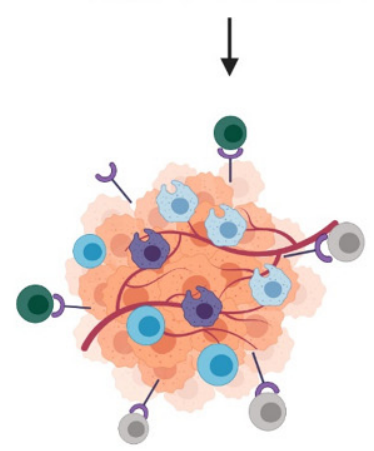

Increased tumor growth and angiogenesis
Magnesium supplement
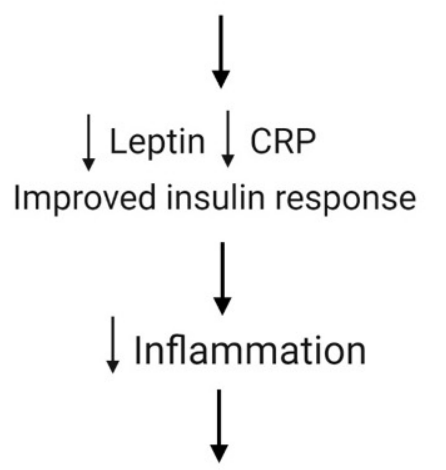

Improved Radiation Response

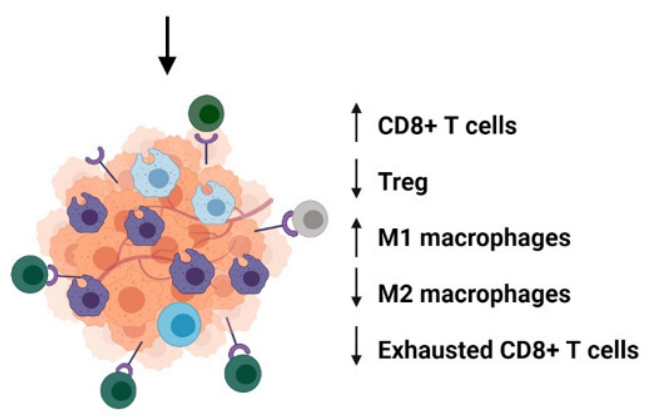

Reduced tumor growth and angiogenesis

Figure 2. Magnesium supplementation to modulate antitumor immune response and radiation sensitivity in breast cancer patients with obesity/metabolic syndrome. Magnesium deficiency is commonly observed in individuals with obesity and metabolic syndrome and is associated with increased insulin resistance and inflammation in these patients, leading to radiation resistance and tumor growth. Modeling supplementation with Magnesium, radiation response would be improved by increasing insulin sensitivity and antitumor immune response. Created with BioRender.com.

\section{Breast Cancer and Radiation Response in Aged Population}

\subsection{Aging and Breast Cancer: Influence of Immune Dysfunction}

The vast majority of cancers are associated with aging and the incidence increases drastically with chronologic age. Currently, the aptly named "silver tsunami", or a rise in the aging population, will bring a shift in the cancer patient population with approximately half of all cancers diagnosed in adults aged $\geq 65$. However, it is believed that in less than 10 years, $70 \%$ of all cancer will occur among those 65 and older [97]. A recent SEER analysis estimates that due to the increasing aging population, the incidence of invasive breast cancer cases could double by 2030, and women older than 70 will make an increasing proportion of those cases [98].

Understanding the reasons behind the increase in cancer incidence in this population at a cellular level is challenging. It has become apparent that older adults have metabolic dysfunctions that may contribute to the development of cancer as well as influence cancer treatment outcomes. As it pertains to aging, possible realistic explanations for the associa- 
tion with increased breast cancer incidence, pathogenies, and tumor progression include the relationship between age-related inflammation, DNA damage, immune cell senescence, and increased adipose with changes seen in metabolic and immune function. As humans age, there are changes in metabolic function with an intimate interplay with the immune system. With age, there is an accumulation of senescent cells or cells that have lost their ability to proliferate. These cells occur throughout life; however, the ability to clear them decreases with aging. Interestingly, even with the cells losing their ability to proliferate, they still have high metabolic activity [99]. There is a metabolic change that occurs shifting toward glycolytic metabolism even with oxygen present. Shifts in metabolism increase AMP and ADP and activate AMPK. This so-called aerobic glycolysis is known as the Warburg Effect and has been shown to promote tumorigenesis and cancer progression [100]. Studies have shown some specific metabolic changes that occur in immune cells with aging. For example, there is a metabolic difference in elderly $\mathrm{T}$ cells with these cells having a lack of substrate for mitochondrial respiration. In this circumstance, they enter the pentose phosphate pathway and an anabolic state [101]. This accumulates NADPH, and there is an upregulation of AMPK, targeting dual-specificity protein phosphatase, which, in turn, regulates MAPK. Overall, this process leads to a decrease in proper T-cell function, leading to a more protumor environment.

The decline in immune function, particularly the adaptive immune response, with aging is known as immunosenescence. The overall lymphoid numbers decrease, with the greatest change in function observed in T cells [102]. Aging causes increased proinflammatory memory $\mathrm{T}$ cells and decreases the number of naïve $\mathrm{T}$ cells. This whole process is likely linked to the chronic inflammation seen in aging, or "inflammaging" [103]. In breast cancer, several studies have correlated "inflammaging" with changes in micro-RNA and chronic inflammation. These non-coding RNAs regulate gene expression and have been shown to influence the inflammatory state seen in the elderly, for example, increased levels of microRNA-21 have been observed in invasive breast cancers [104]. A recent study of breast cancer patients found aging was linked to lower levels of lymphocyte infiltration and decreased CD8 cells. The researchers ultimately compared these observed changes with clinical frailty and found a correlation between immune changes and frailty [105]. Specifically, in breast cancer, there is evidence that this inflammation-shifted immune system influences the increased risk of breast cancer and worse prognosis in this aging patient population. [106] Another pathway where aging metabolism affects immune response can be exemplified by the age-related changes in adipose accumulation, which is also associated with an immune-suppressive environment.

\subsection{Radiation Therapy Outcomes and Toxicity in Older Patients}

While outcomes in the elderly population could be impacted by a diagnosis at a later stage of disease or undertreatment, it is likely age-associated changes in metabolism, immune function, and inflammation play a role $[107,108]$. Understanding the biological process that truly underlies aging as it relates to cancer and the ability to tolerate cancer treatment will be the next large step in individualizing care in this important and growing geriatric population [109].

In addition to biological factors, there are socioeconomic factors that may contribute. While poverty is linked with worse breast cancer outcomes in general, roughly 1 in 3 adults older than 65 in the United States are economically insecure [110]. More older women live in poverty, with a potential explanation being wage discrimination and time away from work to raise kids. Economic inequity can lead to worse nutrition, poor access to food, and a lack of education on healthy lifestyle choices. There is an increased number of comorbidities including obesity and diabetes. The International Agency for Research on Cancer reported up to a third of all cancer cases are linked with increased weight and lack of physical activity [111,112]. It has been shown that obesity and poor nutrition accelerates premature aging, and it stands to reason that the biological explanation for increased cancer 
and worse outcomes associated with some of these factors is related to the changes in cellular metabolism and immune function previously described.

In oncology, there has been growing interest in predicting and improving the difference in cancer treatment outcomes and side effects seen in geriatric patients. There exist validated tools to help predict chemotherapy toxicity in this population. Unfortunately, the data regarding outcomes and side effects of radiation in the aging population are sparse. It is known, however, that our older adult population has increasing difficulty with radiationinduced fatigue, which is more pronounced in more frail patients [113].

\subsection{Zinc Supplementation to Improve Radiation Response}

As life expectancy increases, we will need to continue to research novel approaches to optimize radiation response despite changes in metabolism and immune function in our aging population.

As the medical community continues to learn about the interplay between aging, metabolism, and immune function as it relates to cancer, solutions such as a precision nutritional approach with nutrients such as zinc to narrow the health disparity discussed may be feasible [114]. Even minor deficiencies in Zinc can have large cellular effects [115,116]. Zinc deficiency is associated with increased breast cancer incidence and disease progression [117]. Higher zinc levels have been linked with decreases in breast cancer, and in animal models, zinc supplementation has been shown to decrease breast cancer. High levels of zinc supplementation had a positive effect on reducing oxidative stress and improving immune responses in cancer patients and can also improve response to radiation $[118,119]$.

Zinc levels also have implications on immune function, which may explain the improved breast cancer outcomes and response to radiation. These findings may be related to the effect, or lack thereof, that zinc has on metabolic and immune function with aging. For the first time, in their in vitro study, Dierichs et al. showed that zinc supplementation is able to influence the polarization of human-derived macrophages. They used HLA-DR as an M1 marker and Dectin-1 for M2. Zinc supplementation via high extracellular $\mathrm{Zn}^{2+}$ resulted in increased HLA-DR and decreased Dectin-1, signifying that Zinc promoted M1 polarization while decreasing M2 [120]. Clinically, eliminating macrophages in tumor cells and the microenvironment is a large challenge. One approach may be to change the polarization from protumor to antitumor using agents such as zinc. Other studies have shown zinc deficiency affecting T-cell activation, and a randomized, controlled trial carried out on elderly adults showed that $25 \mathrm{mg}$ of zinc sulfate for 3 months increased the levels of activated T cells [121].

The implications of metabolism and aging immune function are clearly becoming more important as the average population of the United States shifts to an older and likely more obese one. In Figure 3, we summarize the factors that contribute to poor radiation response in the older adult population. We hypothesize that incorporating a targeted treatment approach for the aging population, using zinc supplementation to alter metabolism and immune response, may help in altering the response to radiation for the older adult population with breast cancer. 


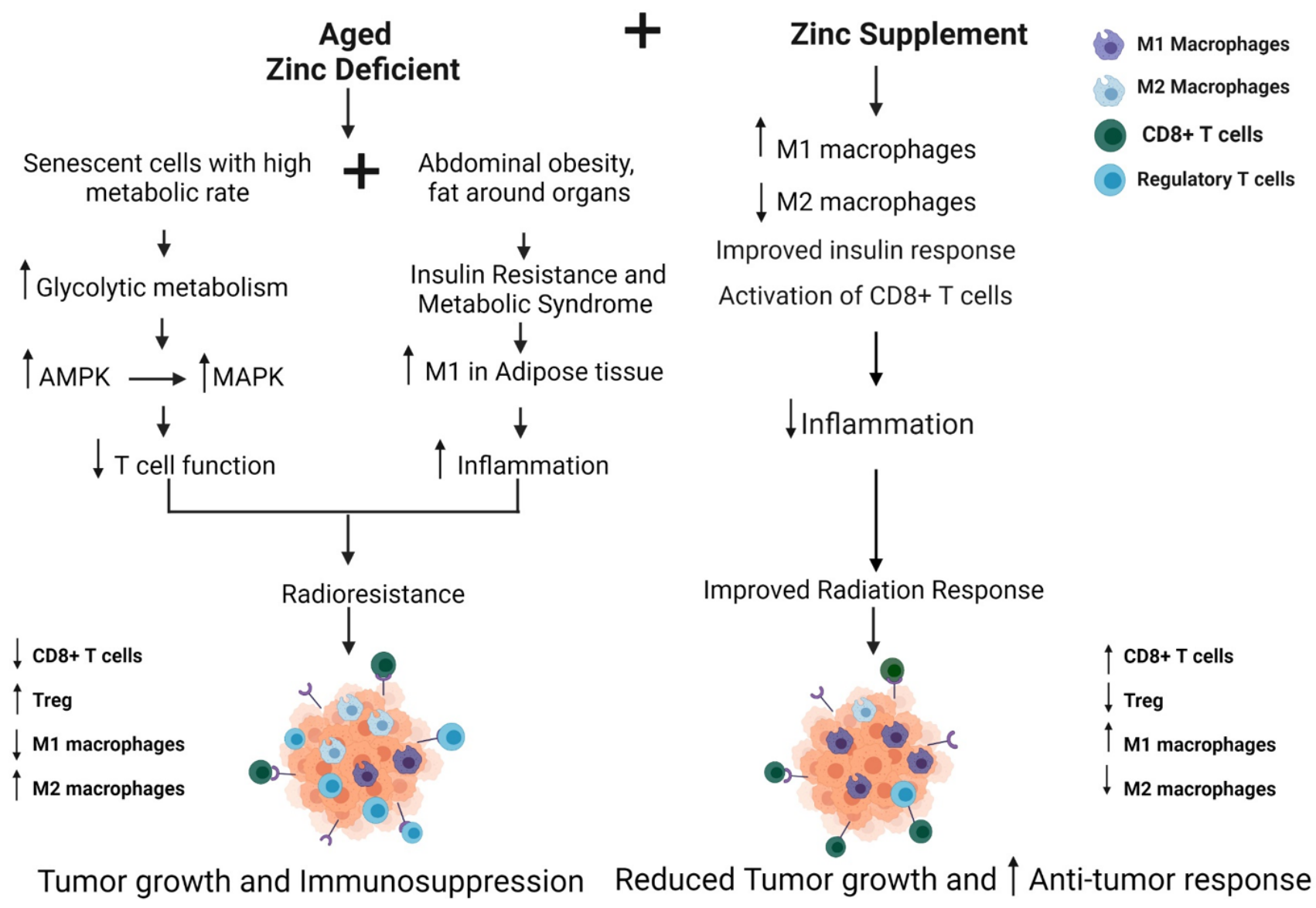

Figure 3. Zinc supplementation to modulate antitumor immune response and radiation sensitivity in the senior adult breast cancer patient. Older women show abdominal obesity and insulin resistance with inflamed adipose tissue and possess senescent cells that show elevated glycolytic metabolism, leading to reduced T-cell function and immunosuppression. Zinc deficiency is commonly observed in older women. Modeling supplementation with Zinc, radiation response would be improved by reducing inflammation and improving insulin and immune response, thereby reducing breast cancer tumor growth $[108,117,121]$. Created with BioRender.com.

\section{Conclusions}

Optimizing radiation therapy will ultimately need to account for both tumor characteristics and patient characteristics. The disparity in interpatient tumor response is likely due to metabolic and immune dysregulation of the patients. Understanding patient populations and underlying molecular dysregulation will provide insight into optimizing response to radiation. Specific metabolic states or trends are predictable in patient populations and learning to account for variations will ensure more equitable radiation delivery. Implementing a precision nutrition approach during radiation therapy, with the goal of improving population-specific metabolic disruptions, may allow for the augmentation of radiation therapy. Further clinical trials need to be conducted to test different dietary supplements as enhancers of radiation therapy.

Author Contributions: Conceptualization-A.A.S., J.L. and N.L.S.; methodology-A.A.S., J.L. and N.L.S.; writing—original draft preparation, A.A.S., J.L., S.C.O., S.H., B.C.S., T.D., A.P., K.H., D.A.M., S.V., E.P.M. and N.L.S.; writing-review and editing-A.A.S., J.L. and N.L.S.; visualization-A.A.S., J.L. and N.L.S.; supervision-N.L.S.; funding acquisition-N.L.S. All authors have read and agreed to the published version of the manuscript.

Funding: This work was funded by National Cancer Institute, R01CA227479 (NLS), and NCI Cancer Center Grant, P30CA056036 (NLS). 
Institutional Review Board Statement: Not applicable.

Informed Consent Statement: Not applicable.

Data Availability Statement: The data that support the findings of this study are available from the corresponding author upon reasonable request.

Acknowledgments: This work is supported by R01CA227479 (NLS), and the NCI Cancer Center Grant P30CA056036 (NLS) supported the Translational Research/Pathology and Lab Animals core facilities.

Conflicts of Interest: The authors declare no conflict of interest.

\section{References}

1. Balaji, K.; Subramanian, B.; Yadav, P.; Radha, C.A.; Ramasubramanian, V. Radiation therapy for breast cancer: Literature review. Med. Dosim. 2016, 41, 253-257. [CrossRef] [PubMed]

2. Early Breast Cancer Trialists' Collaborative Group. Effect of radiotherapy after breast-conserving surgery on 10-year recurrence and 15-year breast cancer death: Meta-analysis of individual patient data for 10,801 women in 17 randomised trials. Lancet 2011, 378, 1707-1716. [CrossRef]

3. Aristei, C.; Perrucci, E.; Alì, E.; Marazzi, F.; Masiello, V.; Saldi, S.; Ingrosso, G. Personalization in Modern Radiation Oncology: Methods, Results and Pitfalls. Personalized Interventions and Breast Cancer. Front. Oncol. 2021, 11, 461. [CrossRef] [PubMed]

4. Loibl, S.; Poortmans, P.; Morrow, M.; Denkert, C.; Curigliano, G. Breast cancer. Lancet 2021, 397, 1750-1769. [CrossRef]

5. Torres-Roca, J.F. A molecular assay of tumor radiosensitivity: A roadmap towards biology-based personalized radiation therapy. Pers. Med. 2012, 9, 547-557. [CrossRef]

6. McCall, N.S.; Simone, B.A.; Mehta, M.; Zhan, T.; Ko, K.; Nowak-Choi, K.; Rese, A.; Venkataraman, C.; Andrews, D.W.; Anne', P.R.; et al. Onco-metabolism: Defining the prognostic significance of obesity and diabetes in women with brain metastases from breast cancer. Breast Cancer Res. Treat. 2018, 172, 221-230. [CrossRef] [PubMed]

7. Sail, K.; Franzini, L.; Lairson, D.; Du, X. Differences in treatment and survival among African-American and Caucasian women with early stage operable breast cancer. Ethn. Health 2012, 17, 309-323. [CrossRef] [PubMed]

8. Coghill, A.E.; Suneja, G.; Rositch, A.F.; Shiels, M.S.; Engels, E.A. HIV Infection, Cancer Treatment Regimens, and Cancer Outcomes Among Elderly Adults in the United States. JAMA Oncol. 2019, 5, e191742. [CrossRef]

9. Chaudhary, N.; Kumar, V.; Sangwan, P.; Pant, N.C.; Saxena, A.; Joshi, S.; Yadav, A.N. 3.36—Personalized Nutrition and -Omics, in Comprehensive Foodomics; Cifuentes, A., Ed.; Elsevier: Oxford, UK, 2021; pp. 495-507.

10. Kviatcovsky, D.; Zheng, D.; Elinav, E. Gut microbiome and its potential link to personalized nutrition. Curr. Opin. Physiol. 2021, 22, 100439. [CrossRef]

11. Ames, B.N.; Wakimoto, P. Are vitamin and mineral deficiencies a major cancer risk? Nat. Rev. Cancer 2002, 2, 694-704. [CrossRef] [PubMed]

12. Aguirre-Portolés, C.; Fernández, L.P.; Ramirez de Molina, A. Precision Nutrition for Targeting Lipid Metabolism in Colorectal Cancer. Nutrients 2017, 9, 1076. [CrossRef] [PubMed]

13. Reglero, C.; Reglero, G. Precision Nutrition and Cancer Relapse Prevention: A Systematic Literature Review. Nutrients 2019, 11, 2799. [CrossRef] [PubMed]

14. Kolodziejczyk, A.A.; Zheng, D.; Elinav, E. Diet-microbiota interactions and personalized nutrition. Nat. Rev. Microbiol. 2019, 17, 742-753. [CrossRef]

15. Ganesan, K.; Jayachandran, M.; Xu, B. Diet-Derived Phytochemicals Targeting Colon Cancer Stem Cells and Microbiota in Colorectal Cancer. Int. J. Mol. Sci. 2020, 21, 3976. [CrossRef]

16. DeSantis, C.E.; Fedewa, S.A.; Sauer, A.G.; Kramer, J.L.; Smith, R.A.; Jemal, A. Breast cancer statistics, 2015: Convergence of incidence rates between black and white women. CA Cancer J. Clin. 2015, 66, 31-42. [CrossRef] [PubMed]

17. Arciero, C.A.; Yang, J.; Peng, L.; Ward, K.C.; O’Regan, R.; Sahin, A.A.; Li, X. African American patients with breast cancer have worse prognosis than white patients in certain subtypes and stages. Breast Cancer Res. Treat. 2017, 166, 743-755. [CrossRef]

18. Newman, G.; Gonzalez-Perez, R.R. Leptin-cytokine crosstalk in breast cancer. Mol. Cell. Endocrinol. 2013, 382, 570-582. [CrossRef] [PubMed]

19. Gaillard, T. Consequences of Abdominal Adiposity within the Metabolic Syndrome Paradigm in Black People of African Ancestry. J. Clin. Med. 2014, 3, 897-912. [CrossRef]

20. Singh, S.K.; Tan, Q.; Brito, C.; De León, M. Insulin-like growth factors I and II receptors in the breast cancer survival disparity among African-American women. Growth Horm. IGF Res. 2010, 20, 245-254. [CrossRef] [PubMed]

21. Farabaugh, S.M.; Boone, D.; Lee, A.V. Role of IGF1R in Breast Cancer Subtypes, Stemness, and Lineage Differentiation. Front. Endocrinol. 2015, 6, 59. [CrossRef]

22. Dunn, S.E.; Kari, F.W.; French, J.; Leininger, J.R.; Travlos, G.; Wilson, R.; Barrett, J.C. Dietary restriction reduces insulin-like growth factor I levels, which modulates apoptosis, cell proliferation, and tumor progression in p53-deficient mice. Cancer Res. 1997, 57. 
23. Haluska, P.; Shaw, H.M.; Batzel, G.N.; Yin, D.; Molina, J.R.; Molife, L.R.; Yap, T.A.; Roberts, M.L.; Sharma, A.; Gualberto, A.; et al. Phase I dose escalation study of the anti insulin-like growth factor-I receptor monoclonal antibody CP-751,871 in patients with refractory solid tumors. Clin. Cancer Res. 2007, 13, 5834-5840. [CrossRef]

24. Ruggeri, B.A.; Klurfeld, D.; Kritchevsky, D.; Furlanetto, R.W. Caloric restriction and 7,12-dimethylbenz(a)anthracene-induced mammary tumor growth in rats: Alterations in circulating insulin, insulin-like growth factors I and II, and epidermal growth factor. Cancer Res. 1989, 49, 4130-4134. [PubMed]

25. Jin, L.; Lim, M.; Zhao, S.; Sano, Y.; Simone, B.A.; Savage, J.E.; Wickstrom, E.; Camphausen, K.; Pestell, R.G.; Simone, N. The metastatic potential of triple-negative breast cancer is decreased via caloric restriction-mediated reduction of the miR-17 92 cluster. Breast Cancer Res. Treat. 2014, 146, 41-50. [CrossRef] [PubMed]

26. Saleh, A.; Simone, B.; Palazzo, J.; Savage, J.E.; Sano, Y.; Dan, T.; Jin, L.; Champ, C.; Zhao, S.; Lim, M.; et al. Caloric restriction augments radiation efficacy in breast cancer. Cell Cycle 2013, 12, 1955-1963. [CrossRef]

27. Tolcher, A.W.; Sarantopoulos, J.; Patnaik, A.; Papadopoulos, K.; Lin, C.-C.; Rodon, J.; Murphy, B.; Roth, B.; McCaffery, I.; Gorski, K.S.; et al. Phase I, Pharmacokinetic, and Pharmacodynamic Study of AMG 479, a Fully Human Monoclonal Antibody to Insulin-Like Growth Factor Receptor 1. J. Clin. Oncol. 2009, 27, 5800-5807. [CrossRef] [PubMed]

28. Oh, H.; Pfeiffer, R.M.; Falk, R.T.; Horne, H.N.; Xiang, J.; Pollak, M.; Brinton, L.A.; Storniolo, A.M.V.; Sherman, M.E.; Gierach, G.L.; et al. Serum insulin-like growth factor (IGF)-I and IGF binding protein-3 in relation to terminal duct lobular unit involution of the normal breast in Caucasian and African American women: The Susan G. Komen Tissue Bank. Int. J. Cancer 2018, 143, 496-507. [CrossRef]

29. Vadgama, J.V.; Wu, Y.; Datta, G.; Khan, H.; Chillar, R. Plasma Insulin-Like Growth Factor-I and Serum IGF-Binding Protein 3 Can Be Associated with the Progression of Breast Cancer, and Predict the Risk of Recurrence and the Probability of Survival in African-American and Hispanic Women. Oncology 1999, 57, 330-340. [CrossRef]

30. Kaleko, M.; Rutter, W.J.; Miller, A.D. Overexpression of the human insulinlike growth factor I receptor promotes ligand-dependent neoplastic transformation. Mol. Cell. Biol. 1990, 10. [CrossRef]

31. Taunk, N.K.; Goyal, S.; Moran, M.S.; Yang, Q.; Parikh, R.; Haffty, B.G. Prognostic significance of IGF-1R expression in patients treated with breast-conserving surgery and radiation therapy. Radiother. Oncol. 2010, 96, 204-208. [CrossRef]

32. Yanochko, G.M.; Eckhart, W. Type I insulin-like growth factor receptor over-expression induces proliferation and anti-apoptotic signaling in a three-dimensional culture model of breast epithelial cells. Breast Cancer Res. 2006, 8, R18. [CrossRef]

33. Valenciano, A.; Henríquez-Hernández, L.A.; Moreno, M.; Lloret, M.; Lara, P.C. Role of IGF-1 Receptor in Radiation Response. Transl. Oncol. 2012, 5, 1-9. [CrossRef] [PubMed]

34. Teoh, N.C.; Dan, Y.Y.; Swisshelm, K.; Lehman, S.; Wright, J.H.; Haque, J.; Gu, Y.; Fausto, N. Defective DNA strand break repair causes chromosomal instability and accelerates liver carcinogenesis in mice. Hepatology 2008, 47, 2078-2088. [CrossRef] [PubMed]

35. Abdou, Y.; Attwood, K.; Cheng, T.-Y.D.; Yao, S.; Bandera, E.V.; Zirpoli, G.R.; Ondracek, R.P.; Stein, L.; Bshara, W.; Khoury, T.; et al. Racial differences in CD8+ T cell infiltration in breast tumors from Black and White women. Breast Cancer Res. 2020, 22, 62. [CrossRef]

36. Zavala, V.A.; Bracci, P.M.; Carethers, J.M.; Carvajal-Carmona, L.; Coggins, N.B.; Cruz-Correa, M.R.; Davis, M.; de Smith, A.J.; Dutil, J.; Figueiredo, J.C.; et al. Cancer health disparities in racial/ethnic minorities in the United States. Br. J. Cancer 2020, 124, 315-332. [CrossRef] [PubMed]

37. Stenström, J.; Hedenfalk, I.; Hagerling, C. Regulatory T lymphocyte infiltration in metastatic breast cancer-an independent prognostic factor that changes with tumor progression. Breast Cancer Res. 2021, 23, 27. [CrossRef]

38. Komatsu, N.; Hori, S. Full restoration of peripheral Foxp3+ regulatory T cell pool by radioresistant host cells in scurfy bone marrow chimeras. Proc. Natl. Acad. Sci. USA 2007, 104, 8959-8964. [CrossRef]

39. Bos, P.D.; Plitas, G.; Rudra, D.; Lee, S.Y.; Rudensky, A.Y. Transient regulatory T cell ablation deters oncogene-driven breast cancer and enhances radiotherapy. J. Exp. Med. 2013, 210, 2435-2466. [CrossRef]

40. Abdou, Y.; Elkhanany, A.; Attwood, K.; Ji, W.; Takabe, K.; Opyrchal, M. Primary and secondary breast angiosarcoma: Single center report and a meta-analysis. Breast Cancer Res. Treat. 2019, 178, 523-533. [CrossRef]

41. Koru-Sengul, T.; Santander, A.M.; Miao, F.; Sanchez, L.G.; Jorda, M.; Glück, S.; Ince, T.A.; Nadji, M.; Chen, Z.; Penichet, M.L.; et al Breast cancers from black women exhibit higher numbers of immunosuppressive macrophages with proliferative activity and of crown-like structures associated with lower survival compared to non-black Latinas and Caucasians. Breast Cancer Res. Treat. 2016, 158, 113-126. [CrossRef]

42. Schnellhardt, S.; Erber, R.; Büttner-Herold, M.; Rosahl, M.-C.; Ott, O.J.; Strnad, V.; Beckmann, M.W.; King, L.; Hartmann, A.; Fietkau, R.; et al. Accelerated Partial Breast Irradiation: Macrophage Polarisation Shift Classification Identifies High-Risk Tumours in Early Hormone Receptor-Positive Breast Cancer. Cancers 2020, 12, 446. [CrossRef]

43. Mukhtar, R.A.; Moore, A.P.; Nseyo, O.; Baehner, F.L.; Au, A.; Moore, D.H.; Twomey, P.; Campbell, M.J.; Esserman, L.J. Elevated PCNA + tumor-associated macrophages in breast cancer are associated with early recurrence and non-Caucasian ethnicity. Breast Cancer Res. Treat. 2011, 130, 635-644. [CrossRef]

44. O'Meara, T.; Safonov, A.; Casadevall, D.; Qing, T.; Silber, A.; Killelea, B.; Hatzis, C.; Pusztai, L. Immune microenvironment of triple-negative breast cancer in African-American and Caucasian women. Breast Cancer Res. Treat. 2019, 175, 247-259. [CrossRef] [PubMed] 
45. Pitt, J.J.; Riester, M.; Zheng, Y.; Yoshimatsu, T.F.; Sanni, A.; Oluwasola, O.; Veloso, A.; Labrot, E.; Wang, S.; Odetunde, A.; et al. Characterization of Nigerian breast cancer reveals prevalent homologous recombination deficiency and aggressive molecular features. Nat. Commun. 2018, 9, 4181. [CrossRef] [PubMed]

46. Milas, L. Tumor Bed Effect in Murine Tumors: Relationship to Tumor Take and Tumor Macrophage Content. Radiat. Res. 1990, 123, 232. [CrossRef] [PubMed]

47. Tsai, C.-S.; Chen, F.-H.; Wang, C.-C.; Huang, H.-L.; Jung, S.-M.; Wu, C.-J.; Lee, C.-C.; McBride, W.H.; Chiang, C.-S.; Hong, J.-H. Macrophages from Irradiated Tumors Express Higher Levels of iNOS, Arginase-I and COX-2, and Promote Tumor Growth. Int. J. Radiat. Oncol. 2007, 68, 499-507. [CrossRef] [PubMed]

48. Guadagno, E.; Presta, I.; Maisano, D.; Donato, A.; Pirrone, C.K.; Cardillo, G.; Corrado, S.D.; Mignogna, C.; Mancuso, T.; Donato, G.; et al. Role of Macrophages in Brain Tumor Growth and Progression. Int. J. Mol. Sci. 2018, 19, 1005. [CrossRef]

49. Bandera, E.V.; Chandran, U.; Hong, C.-C.; Troester, M.A.; Bethea, T.; Adams-Campbell, L.L.; Haiman, C.A.; Park, S.-Y.; Olshan, A.F.; Ambrosone, C.B.; et al. Obesity, body fat distribution, and risk of breast cancer subtypes in African American women participating in the AMBER Consortium. Breast Cancer Res. Treat. 2015, 150, 655-666. [CrossRef]

50. Dietze, E.C.; Chavez, T.A.; Seewaldt, V.L. Obesity and Triple-Negative Breast Cancer: Disparities, Controversies, and Biology. Am. J. Pathol. 2018, 188, 280-290. [CrossRef]

51. Xie, S.; Pirianov, G.; Colston, K. Vitamin D analogues suppress IGF-I signalling and promote apoptosis in breast cancer cells. Eur. J. Cancer 1999, 35, 1717-1723. [CrossRef]

52. Yu, H.; Rohan, T. Role of the insulin-like growth factor family in cancer development and progression. J. Natl. Cancer Inst. 2000, 92, 1472-1489. [CrossRef] [PubMed]

53. Arensberg, M.; Richards, J.; Benjamin, J.; Kerr, K.; Hegazi, R. Opportunities for Quality Improvement Programs (QIPs) in the Nutrition Support of Patients with Cancer. Healthcare 2020, 8, 227. [CrossRef]

54. Yao, S.; Ambrosone, C.B. Associations between vitamin D deficiency and risk of aggressive breast cancer in African-American women. J. Steroid Biochem. Mol. Biol. 2013, 136, 337-341. [CrossRef] [PubMed]

55. Wu, X.; Hu, W.; Lu, L.; Zhao, Y.; Zhou, Y.; Xiao, Z.; Zhang, L.; Zhang, H.; Li, X.; Li, W.; et al. Repurposing vitamin D for treatment of human malignancies via targeting tumor microenvironment. Acta Pharm. Sin. B 2018, 9, 203-219. [CrossRef] [PubMed]

56. Green, A.K.; Hankinson, S.E.; Bertone-Johnson, E.R.; Tamimi, R.M. Mammographic density, plasma vitamin D levels and risk of breast cancer in postmenopausal women. Int. J. Cancer 2010, 127, 667-674. [CrossRef] [PubMed]

57. Karkeni, E.; Morin, S.O.; Tayeh, B.B.; Goubard, A.; Josselin, E.; Castellano, R.; Fauriat, C.; Guittard, G.; Olive, D.; Nunès, J.A Vitamin D Controls Tumor Growth and CD8+ T Cell Infiltration in Breast Cancer. Front. Immunol. 2019, 10, 1307. [CrossRef]

58. Kim, Y.S.; Sayers, T.J.; Colburn, N.H.; Milner, J.A.; Young, H.A. Impact of dietary components on NK and Treg cell function for cancer prevention. Mol. Carcinog. 2015, 54, 669-678. [CrossRef]

59. Yedjou, C.G.; Sims, J.N.; Miele, L.; Noubissi, F.; Lowe, L.; Fonseca, D.D.; Alo, R.A.; Payton, M.; Tchounwou, P.B. Health and Racial Disparity in Breast Cancer. Adv. Exp. Med. Biol. 2019, 1152, 31-49. [CrossRef]

60. Huang, R.; Xiang, J.; Zhou, P.-K. Vitamin D, gut microbiota, and radiation-related resistance: A love-hate triangle. J. Exp. Clin. Cancer Res. 2019, 38, 493. [CrossRef]

61. Gunter, M.J.; Hoover, D.R.; Yu, H.; Wassertheil-Smoller, S.; Rohan, T.E.; Manson, J.E.; Li, J.; Ho, G.Y.F.; Xue, X.; Anderson, G.L.; et al. Insulin, insulin-like growth factor-I, and risk of breast cancer in postmenopausal women. J. Natl. Cancer Inst. 2009, 101, 48-60. [CrossRef]

62. Hales, C.M.; Carroll, M.D.; Fryar, C.D.; Ogden, C.L. Prevalence of Obesity and Severe Obesity among Adults: United States, 2017-2018; CDC National Center for Health Statistics: Hyattsville, MD, USA, 2020; pp. 1-8.

63. Bhandari, R.; Kelley, G.A.; Hartley, T.A.; Rockett, I.R.H. Metabolic Syndrome Is Associated with Increased Breast Cancer Risk: A Systematic Review with Meta-Analysis. Int. J. Breast Cancer 2014, 2014, 189384. [CrossRef]

64. Neuhouser, M.L.; Aragaki, A.K.; Prentice, R.L.; Manson, J.E.; Chlebowski, R.; Carty, C.L.; Ochs-Balcom, H.M.; Thomson, C.A.; Caan, B.J.; Tinker, J.F.; et al. Overweight, Obesity, and Postmenopausal Invasive Breast Cancer Risk: A Secondary Analysis of the Women's Health Initiative Randomized Clinical Trials. JAMA Oncol. 2015, 1, 611-621. [CrossRef] [PubMed]

65. Biello, F.; Platini, F.; D'Avanzo, F.; Cattrini, C.; Mennitto, A.; Genestroni, S.; Martini, V.; Marzullo, P.; Aimaretti, G.; Gennari, A. Insulin/IGF Axis in Breast Cancer: Clinical Evidence and Translational Insights. Biomolecules 2021, 11, 125. [CrossRef] [PubMed]

66. Atoum, M.F.; Alzoughool, F.; Al-Hourani, H. Linkage Between Obesity Leptin and Breast Cancer. Breast Cancer Basic Clin. Res. 2020, 14, 1178223419898458. [CrossRef] [PubMed]

67. Khandekar, M.J.; Cohen, P.; Spiegelman, B.M. Molecular mechanisms of cancer development in obesity. Nat. Rev. Cancer 2011, 11, 886-895. [CrossRef]

68. Li, Y.R.; Ro, V.; Tchou, J.C. Obesity, Metabolic Syndrome, and Breast Cancer: From Prevention to Intervention. Curr. Surg. Rep. 2018, 6, 7. [CrossRef] [PubMed]

69. Niu, J.; Jiang, L.; Guo, W.; Shao, L.; Liu, Y.; Wang, L. The Association between Leptin Level and Breast Cancer: A Meta-Analysis. PLoS ONE 2013, 8, e67349. [CrossRef] [PubMed]

70. Andò, S.; Gelsomino, L.; Panza, S.; Giordano, C.; Bonofiglio, D.; Barone, I.; Catalano, S. Obesity, Leptin and Breast Cancer: Epidemiological Evidence and Proposed Mechanisms. Cancers 2019, 11, 62. [CrossRef] [PubMed]

71. Naik, A.; Monjazeb, A.M.; Decock, J. The Obesity Paradox in Cancer, Tumor Immunology, and Immunotherapy: Potential Therapeutic Implications in Triple Negative Breast Cancer. Front. Immunol. 2019, 10, 1940. [CrossRef] [PubMed] 
72. Kolb, R.; Zhang, W. Obesity and Breast Cancer: A Case of Inflamed Adipose Tissue. Cancers 2020, 12, 1686. [CrossRef]

73. Deng, T.; Lyon, C.L.; Bergin, S.; Caligiuri, M.A.; Hsueh, W.A. Obesity, Inflammation, and Cancer. Annu. Rev. Pathol. 2016, 11, 421-449. [CrossRef]

74. Petrelli, F.; Cortellini, A.; Indini, A.; Tomasello, G.; Ghidini, M.; Nigro, O.; Salati, M.; Dottorini, L.; Iaculli, A.; Varricchio, A.; et al. Association of Obesity With Survival Outcomes in Patients With Cancer: A Systematic Review and Meta-analysis. JAMA Netw. Open. 2021, 4, e213520. [CrossRef] [PubMed]

75. Jiralerspong, S.; Goodwin, P. Obesity and Breast Cancer Prognosis: Evidence, Challenges, and Opportunities. J. Clin. Oncol. 2016, 34, 4203-4216. [CrossRef] [PubMed]

76. Blair, C.; Wiggins, C.L.; Nibbe, A.M.; Storlie, C.B.; Prossnitz, E.R.; Royce, M.; Lomo, L.C.; Hill, D.A. Obesity and survival among a cohort of breast cancer patients is partially mediated by tumor characteristics. NPJ Breast Cancer 2019, 5, 33. [CrossRef] [PubMed]

77. Lega, I.C.; Austin, P.C.; Fischer, H.D.; Fung, K.; Krzyzanowska, M.K.; Amir, E.; Lipscombe, L.L. The Impact of Diabetes on Breast Cancer Treatments and Outcomes: A Population-Based Study. Diabetes Care 2018, 41, 755-761. [CrossRef]

78. Sabol, R.A.; Villela, V.A.; Denys, A.; Freeman, B.T.; Hartono, A.B.; Wise, R.M.; Harrison, M.A.A.; Sandler, M.B.; Hossain, F.; Miele, L.; et al. Obesity-Altered Adipose Stem Cells Promote Radiation Resistance of Estrogen Receptor Positive Breast Cancer through Paracrine Signaling. Int. J. Mol. Sci. 2020, 21, 2722. [CrossRef] [PubMed]

79. Lee, E.; Takita, C.; Wright, J.L.; Reis, I.M.; Zhao, W.; Nelson, O.L.; Hu, J.J. Characterization of risk factors for adjuvant radiotherapyassociated pain in a tri-racial/ethnic breast cancer population. Pain 2016, 157, 1122-1131. [CrossRef] [PubMed]

80. Rodriguez-Gil, J.L.; Takita, C.; Wright, J.; Reis, I.M.; Zhao, W.; Lally, B.E.; Hu, J.L. Inflammatory biomarker C-reactive protein and radiotherapy-induced early adverse skin reactions in patients with breast cancer. Cancer Epidemiol. Biomark. Prev. 2014, 23, 1873-1883. [CrossRef]

81. Fang, P.; Tan, K.S.; Troxel, A.B.; Rengan, R.; Freedman, G.; Lin, L.L. High body mass index is associated with worse quality of life in breast cancer patients receiving radiotherapy. Breast Cancer Res. Treat. 2013, 141, 125-133. [CrossRef] [PubMed]

82. De Langhe, S.; Mulliez, T.; Veldeman, L.; Remouchamps, V.; Van Greveling, A.; Gilsoul, M.; De Schepper, E.; De Ruyck, K.; De Neve, W.; Thierens, H. Factors modifying the risk for developing acute skin toxicity after whole-breast intensity modulated radiotherapy. BMC Cancer 2014, 14, 711. [CrossRef]

83. Volpe, S.L. Magnesium in Disease Prevention and Overall Health. Adv. Nutr. 2013, 4, 378S-383S. [CrossRef]

84. Guerrero-Romero, F.; Rodríguez-Morán, M. Low serum magnesium levels and metabolic syndrome. Acta Diabetol. 2002, 39, 209-213. [CrossRef] [PubMed]

85. Hruby, A.; Meigs, J.B.; O’Donnell, C.J.; Jacques, P.F.; McKeown, N.M. Higher Magnesium Intake Reduces Risk of Impaired Glucose and Insulin Metabolism and Progression From Prediabetes to Diabetes in Middle-Aged Americans. Diabetes Care 2013, 37, 419-427. [CrossRef] [PubMed]

86. Mooren, F.C.; Krüger, K.; Völker, K.; Golf, S.W.; Wadepuhl, M.; Kraus, A. Oral magnesium supplementation reduces insulin resistance in non-diabetic subjects-A double-blind, placebo-controlled, randomized trial. Diabetes Obes. Metab. 2011, 13, 281-284. [CrossRef] [PubMed]

87. Cahill, F.; Shahidi, M.; Shea, J.; Wadden, D.; Gulliver, W.; Randell, E.; Vasdev, S.; Sun, G. High Dietary Magnesium Intake Is Associated with Low Insulin Resistance in the Newfoundland Population. PLoS ONE 2013, 8, e58278. [CrossRef] [PubMed]

88. Cortés, Y.E.; Moses, L. Magnesium disturbances in critically ill patients. Compend. (Yardley PA) 2007, $29,420$.

89. Son, E.-W.; Lee, S.-R.; Choi, H.-S.; Koo, H.-J.; Huh, J.-E.; Kim, M.-H.; Pyo, S. Effects of supplementation with higher levels of manganese and magnesium on immune function. Arch. Pharmacal Res. 2007, 30, 743-749. [CrossRef]

90. Huang, W.-Q.; Long, W.-Q.; Mo, X.-F.; Zhang, N.; Luo, H.; Lin, F.-Y.; Huang, J.; Zhang, C.-X. Direct and indirect associations between dietary magnesium intake and breast cancer risk. Sci. Rep. 2019, 9, 5764. [CrossRef]

91. Anastassopoulou, J.; Theophanides, T. Magnesium-DNA interactions and the possible relation of magnesium to carcinogenesis. Irradiation and free radicals. Crit. Rev. Oncol. Hematol. 2002, 42, 79-91. [CrossRef]

92. Wolf, F.; Maier, J.A.M.; Nasulewicz-Goldeman, A.; Feillet-Coudray, C.; Simonacci, M.; Mazur, A.; Cittadini, A. Magnesium and neoplasia: From carcinogenesis to tumor growth and progression or treatment. Arch. Biochem. Biophys. 2006, 458, 24-32. [CrossRef]

93. Mendes, P.M.V.; Bezerra, D.L.C.; dos Santos, L.R.; de Oliveira Santos, R.; de Sousa Melo, S.R.; Morais, J.B.S.; Severo, J.S.; Vieira, C.; do Nascimento Marreiro, D. Magnesium in Breast Cancer: What Is Its Influence on the Progression of This Disease? Biol. Trace Elem. Res. 2018, 184, 334-339. [CrossRef] [PubMed]

94. Darbari, D.S.; Ballas, S.K.; Clauw, D.J. Thinking beyond sickling to better understand pain in sickle cell disease. Eur. J. Haematol. 2014, 93, 89-95. [CrossRef] [PubMed]

95. De la Cruz-Morcillo, M.A.; García-Cano, J.; Arias-González, L.; García-Gil, E.; Artacho-Cordón, F.; Ríos-Arrabal, S.; Valero, M.L.; Cimas, F.J.; Serrano-Oviedo, L.; Villas, M.V.; et al. Abrogation of the p38 MAPK alpha signaling pathway does not promote radioresistance but its activity is required for 5-Fluorouracil-associated radiosensitivity. Cancer Lett. 2013, 335, 66-74. [CrossRef] [PubMed]

96. Thornton, T.M.; Rincon, M. Non-Classical P38 Map Kinase Functions: Cell Cycle Checkpoints and Survival. Int. J. Biol. Sci. 2009, 5, 44-52. [CrossRef] [PubMed]

97. White, M.C.; Holman, D.M.; Boehm, J.E.; Peipins, L.A.; Grossman, M.; Henley, J. Age and cancer risk: A potentially modifiable relationship. Am. J. Prev. Med. 2014, 46 (Suppl. 1), S7-S15. [CrossRef] 
98. NCI. Study Forecasts New Breast Cancer Cases by 2030. 2021. Available online: https://www.cancer.gov/news-events/cancercurrents-blog/2015/breast-forecast (accessed on 23 December 2021).

99. Haynes, L. Aging of the Immune System: Research Challenges to Enhance the Health Span of Older Adults. Front. Aging 2020, 1, 2. [CrossRef]

100. Johnson, S.; Rabinovitch, P.S.; Kaeberlein, M. mTOR is a key modulator of ageing and age-related disease. Nature 2013, 493, 338-345. [CrossRef] [PubMed]

101. Weyand, C.M.; Goronzy, J.J. Aging of the Immune System. Mechanisms and Therapeutic Targets. Ann. Am. Thorac. Soc. 2016, 13 (Suppl. 5), S422-S428. [CrossRef] [PubMed]

102. Aw, D.; Silva, A.B.; Palmer, D.B. Immunosenescence: Emerging challenges for an ageing population. Immunology 2007, 120, 435-446. [CrossRef] [PubMed]

103. Santoro, A.; Bientinesi, E.; Monti, D. Immunosenescence and inflammaging in the aging process: Age-related diseases or longevity? Ageing Res. Rev. 2021, 71, 101422. [CrossRef]

104. Catana, C.S.; Calin, G.A.; Berindan-Neagoe, I. Inflamma-miRs in Aging and Breast Cancer: Are They Reliable Players? Front. Med. 2015, 2, 85. [CrossRef] [PubMed]

105. Berben, L.; Floris, G.; Kenis, C.; Dalmasso, B.; Smeets, A.; Vos, H.; Neven, P.; Martinez, A.A.; Laenen, A.; Wildiers, H.; et al. Age-related remodelling of the blood immunological portrait and the local tumor immune response in patients with luminal breast cancer. Clin. Transl. Immunol. 2020, 9, e1184. [CrossRef] [PubMed]

106. Deleidi, M.; Jäggle, M.; Rubino, G. Immune aging, dysmetabolism, and inflammation in neurological diseases. Front. Neurosci. 2015, 9, 172. [CrossRef] [PubMed]

107. Nelson, H.D. Menopause. Lancet 2008, 371, 760-770. [CrossRef]

108. Tesarova, P. Breast cancer in the elderly-Should it be treated differently? Rep. Pract. Oncol. Radiother. 2012, 18, 26-33. [CrossRef] [PubMed]

109. Kocik, J.; Pajączek, M.; Kryczka, T. Worse survival in breast cancer in elderly may not be due to underutilization of medical procedures as observed upon changing healthcare system in Poland. BMC Cancer 2019, 19, 749. [CrossRef]

110. Cubanski, J.; Koma, W. How Many Seniors Live in Poverty? 2018. Available online: https://files.kff.org/attachment/Issue-BriefHow-Many-Seniors-Live-in-Poverty (accessed on 1 December 2021).

111. Kruger, J.; Kohl, H.W., III; Miles, I.J. Prevalence of regular physical activity among adults-United States, 2001 and 2005. MMWR Morb. Mortal Wkly. Rep. 2007, 56, 1209-1212.

112. Connolly, B.S.; Barnett, C.; Vogt, K.N.; Li, T.; Stone, J.; Boyd, N.F. A Meta-Analysis of Published Literature on Waist-to-Hip Ratio and Risk of Breast Cancer. Nutr. Cancer 2002, 44, 127-138. [CrossRef]

113. Denkinger, M.M.D.; Hasch, M.; Gerstmayer, A.; Kreienberg, R.; Nikolaus, T.; Hancke, K. Predicting fatigue in older breast cancer patients receiving radiotherapy. Z. Gerontol. Geriatr. 2015, 48, 128-134. [CrossRef] [PubMed]

114. Aiello, A.; Farzaneh, F.; Candore, G.; Caruso, C.; Davinelli, S.; Gambino, C.M.; Ligotti, M.E.; Zareian, N.; Accardi, G. Immunosenescence and Its Hallmarks: How to Oppose Aging Strategically? A Review of Potential Options for Therapeutic Intervention. Front. Immunol. 2019, 10, 2247. [CrossRef] [PubMed]

115. Maggini, S.; Pierre, A.; Calder, P.C. Immune Function and Micronutrient Requirements Change over the Life Course. Nutrients 2018, 10, 1531. [CrossRef]

116. Haase, H.; Rink, L. The immune system and the impact of zinc during aging. Immun. Ageing 2009, 6, 9. [CrossRef] [PubMed]

117. Wu, X.; Tang, J.; Xie, M. Serum and hair zinc levels in breast cancer: A meta-analysis. Sci. Rep. 2015, 5, 12249. [CrossRef] [PubMed]

118. Taysi, S.; Uzun, N.; Tarakcioglu, M.; Adli, M.; Aksoy, A.; Okumus, S.; Akyüz, M.; Demir, E.; Orkmez, M. Zinc administration modulates radiation-induced oxidative injury in lens of rat. Pharmacogn. Mag. 2012, 8, 245-249. [CrossRef] [PubMed]

119. Federico, A.; Iodice, P.; Del Río, A.; Mellone, M.C.; Catalano, G.; Federico, P. Effects of selenium and zinc supplementation on nutritional status in patients with cancer of digestive tract. Eur. J. Clin. Nutr. 2001, 55, 293-297. [CrossRef] [PubMed]

120. Dierichs, L.; Kloubert, V.; Rink, L. Cellular zinc homeostasis modulates polarization of THP-1-derived macrophages. Eur. J. Nutr. 2017, 57, 2161-2169. [CrossRef] [PubMed]

121. Prasad, A.S. Zinc in Human Health: Effect of Zinc on Immune Cells. Mol. Med. 2008, 14, 353-357. [CrossRef] 